Código JEL: K0

\title{
El contrato de leasing. Su regulación en la Ley Concursal y en la Legge Fallimentare
}

\author{
Sonia MARTÍN MARTÍN \\ Abogada \\ Colaboradora honorífica del Departamento de Derecho Mercantil de la Universidad \\ Complutense de Madrid \\ soniammartin@yahoo.es
}

Recibido: 10-12-2013

Aceptado: 16-02-2014

\section{RESUMEN}

Dada la complejidad que en estos últimos años ha presentado el contrato de leasing en materia concursal, se ha realizado un estudio de la regulación de dicho contrato en la Ley Concursal y en la Legge Fallimentate (Ley Concursal). Primero, se analizará el contrato de leasing en la Ley Concursal, donde se pormenorizará sobre las diferentes interpretaciones que se recogen en numerosas sentencias dictadas por los Jueces de lo Mercantil, haciéndose especial referencia a las cuotas pendientes posteriores a la declaración de concurso. Después, en el estudio del Derecho Concursal italiano, se expondrá la regulación del contrato de leasing antes de la reforma del año 2006 de la Legge Fallimentare, para finalizar dicho estudio en su actual legislación.

Palabras clave: Ley, Concursal, Contrato, Leasing. 


\title{
The regulation of the Leasing Contract in the Spanish Ley Concursal (Bankrupcy Law) and the Italian Legge Fallimentare
}

\begin{abstract}
Due to the complexity deriving from the leasing contract within bankruptcy legislation in recent years, an analysis of the said contract is carried out in the Spanish Ley Concursal (bankruptcy law) and the Italian Legge Fallimentate. Firstly, the contract of leasing in Spanish bankruptcy law is analysed, giving detailed consideration to the different interpretations it has been given in numerous sentences by the judges of the commercial courts, particularly in connection with payments whose due date is later than the date of filing for bankruptcy. Secondly, in the study of Italian bankruptcy law, the legislation of the leasing contract is first examined prior to the 2006 Legge Fallimentate reform and finally the situation is analysed in the light of the current legislation.
\end{abstract}

Keywords: Law, Concursal, Contract, Leasing.

Sumario: 1. Introducción; 2. Regulación del leasing en la Ley Concursal; 3. Regulación del leasing en la Legge Fallimentare; 4. Conclusión; Bibliografía.

\section{INTRODUCCIÓN}

El aumento de la riqueza material de un país necesita ir acompañado de un desarrollo de su superestructura financiera, de manera que sin un sistema financiero moderno difícilmente, más bien imposible, un país puede seguir una senda de crecimiento económico. Así, en el siglo XIX en Estados Unidos y con motivo de las construcciones ferroviarias, se realizaron contratos semejantes a lo que hoy conocemos como leasing, ya que hasta 1952 no se recogió en el lenguaje mercantil, considerándolo como aquellas operaciones de arrendamiento financiero de bienes que reunen determinadas condiciones. En la actualidad, a nivel internacional, debemos de destacar el Convenio Unidroit de Ottawa (Cánada) de 20 de mayo de 1988, sobre leasing mobiliario internacional. En el caso de España, aunque no ha ratificado su contenido, sí es relevante a efectos interpretativos en algunos supuestos prácticos.

En España, a partir de la liberación de 1977, tuvo lugar un proceso de innovación financiera, tanto en lo que se refiere a la generación de nuevos productos financieros, como a nuevos servicios y a la creación de nuevas instituciones financieras. Una de estas instituciones financieras fueron las sociedades de arrendamiento financiero o leasing. Así, el concepto del contrato de leasing habría venido regulado en un primer momento por el RDL 15/1977, de 25 de febrero, de medidas fiscales financieras y de inversión pública, en el que se 
delimitaba a efectos fiscales. Posteriormente, la Ley 26/1988, de 29 de julio, sobre Disciplina e Intervención de las Entidades de Crédito, derogando expresamente el Título II de RDL 15/1977, de 25 de febrero, sobre "las empresas de arrendamiento financiero", en su Disposición Adicional Séptima, pretendió introducir modificaciones en el tratamiento fiscal del leasing y ofrecer, además, una regulación sustantiva, que resultó ser insuficiente. Por último, la Ley 28/1998, 13 de julio de Venta a Plazos de Bienes Muebles (posteriormente LVPBM), en su Disposición Adicional Primera, la cual se remite a la Ley 26/1988, de 29 de julio, sobre Disciplina e Intervención de las Entidades de Crédito, dado que, ésta última, recoge la siguiente definición del contrato de leasing: “Tendrán la consideración de operaciones de arrendamiento financiero aquellos contratos que tengan por objeto exclusivo la cesión del uso de bienes muebles o inmuebles, adquiridos para dicha finalidad según las especificaciones del futuro usuario, a cambio de una contraprestación consistente en el abono periódico de las cuotas (...). El contrato de arrendamiento financiero incluirá necesariamente una opción de compra, a su término, en favor del usuario".

Se trata de un contrato atípico, complejo y mercantil, diferente a la compraventa a plazos con opción de compra, al arrendamiento y al comodato o préstamo de uso, aunque a veces se ha equiparado al primero. De ahí la importancia de lo pactado por las partes contratantes, siendo la autonomía de la voluntad la principal fuente de la reglamentación del contrato, a tenor de lo establecido en los artículos 1255 y 1258 del Código civil, siempre y cuando tal autonomía no contravenga alguna norma imperativa. En el contrato de leasing existen tres partes: por un lado, el usuario o arrendatario, quien para ejercer su actividad necesita un determinado bien; por otro, la entidad de leasing, que es un intermediario financiero que adquiere el bien que precisa el usuario; y por otro, el fabricante o vendedor del bien en cuestión.

\section{REGULACIÓN DEL LEASING EN LA LEY CONCURSAL}

Una vez definido el contrato de arrendamiento financiero, pasaremos a analizar su regulación en la Ley Concursal (posteriormente, LC). Para obtener una visión completa tendremos que hacer una mención a la regulación anterior a dicha ley. Así, si cuando el usuario era declarado en quiebra y el contrato de leasing estaba en vigor, la entidad de leasing podía pedir la resolución del contrato e insinuar el importe de la indemnización por daños y perjuicios en la masa de acreedores como créditos ordinarios, salvo que los síndicos solicitaran la subsistencia del contrato. En caso de resolución, la entidad de leasing tenía derecho a la devolución de la cosa (arts. 908 y 909 CCo), y que ha sido posteriormente regulada para los contratos de leasing financieros inscritos en el Registro de Bienes Muebles por el $\mathrm{n}$ 5, aps 2 y 3 de la DA $1^{\circ}$ LVPBM de 1998. La suspensión de pagos se regulaba en 
el ap. 1 del n 5, aps 2 y 3 de la DA $1^{\circ}$ LVPBM de 1998 destacando el derecho de abstención del arrendador financiero en el convenio y la posibilidad de ejercitar sus derechos de forma separada. En la Ley Concursal, en tanto el usuario cumpla con sus obligaciones, tiene derecho a usar el bien objeto del leasing y a poder acceder a su propiedad satisfaciendo el importe de la opción de compra. De esta forma, la entidad de leasing no puede resolver el contrato, de acuerdo, con lo establecido en el art. 61.2 I LC: "La declaración de concurso, por si sola, no afectará a la vigencia de los contratos con obligaciones recíprocas pendientes de cumplimiento tanto a cargo del concursado como de la otra parte. Las prestaciones a que esté obligado el concursado se realizarán con cargo a la masa”. Así, cabe destacar que por declararse en concurso no afecta a la vigencia del contrato a diferencia de la anterior regulación.

Por el contrario, el concursado podrá solicitar la resolución del contrato según lo establecido en el art. 61.2 II LC: "No obstante lo dispuesto en el párrafo anterior, la administración concursal, en caso de suspensión, o el concursado, en caso de intervención, podrán solicitar la resolución del contrato si lo estimaran conveniente al interés del concurso. El Secretario judicial citará a comparecencia ante el Juez al concursado, a la administración concursal y a la otra parte en el contrato y, de existir acuerdo en cuanto a la resolución y sus efectos, el Juez dictará auto declarando resuelto el contrato de conformidad con lo acordado. En otro caso, las diferencias se sustanciarán por los trámites del incidente concursal y el Juez decidirá acerca de la resolución, acordando, en su caso, las restituciones que procedan y la indemnización que haya de satisfacer con cargo a la masa.” A lo que debemos de añadir que ha sido modificado por la Ley 38/2011, de 10 de octubre, de reforma de a Ley 22/2003, de 9 de julio, Concursal, la cual dice que: "Cuando se trate de la resolución de contratos de arrendamiento financiero, y a falta de acuerdo entre las partes, con la demanda incidental se acompañará tasación pericial independiente de los bienes cedidos que el juez podrá tener en cuenta al fijar la indemnización”.

Se puede concluir que el art. 61.2 regula aquellos contratos con obligaciones reciprocas pendientes de cumplimiento. Es, por ello, que antes de comenzar el estudio de las cuotas pendientes del contrato de arrendamiento financiero, debemos citar la regulación de las obligaciones pendientes de una de las partes. A este respecto, el art. 61.1 LC establece que: "En los contratos celebrados por el deudor, cuando al momento de la declaración del concurso una de las partes hubiera cumplido íntegramente sus obligaciones y la otra tuviese pendiente el cumplimiento total o parcial de las recíprocas a su cargo, el crédito o la deuda que corresponda al deudor se incluirá, según proceda, en la masa activa o en la pasiva del concurso". Por último, nos remitiremos al art. 90. $1.4^{\circ}$ en el que se determina los créditos con privilegio especial: "Son créditos con privilegio especial: (...) $4^{\circ}$ Los créditos por cuotas de arrendamiento financiero o plazos de compra ventas con precio aplazado de bienes de muebles o inmuebles, a favor de los 
arrendadores o vendedores, y en su caso, de los financiadores, sobre los bienes arrendados o vendidos con reserva de dominio con prohibición de disponer o con condición resolutoria en caso de falta de pago. Ante la regulación expuesta anteriormente, el problema se plantea al aplicar el artículo 61 LC debido a si las cuotas pendientes del contrato de leasing se consideran "créditos concursales" o "contra la masa”, ya que en el primer caso se aplicará el párrafo primero del citado artículo, y en el segundo, es decir, "contra la masa”, se regularía por el segundo apartado. Ambos criterios vienen establecidos por las dos corrientes existentes en la actualidad: una mayoritaria, la cual defiende la aplicación del art. 61.2 basándose en considerar al leasing como un contrato sinalagmático de tracto sucesivo con obligaciones pendientes de cumplimiento. Y la segunda corriente, minoritaria, la cual, a diferencia de la anterior, considera al arrendamiento financiero como un contrato de tracto único con obligaciones de cumplimiento únicamente por parte del arrendatario financiero deudor concursado, por lo que se aplicaría el art. 61.1 LC. Esta última esta tomando más relevancia en estos últimos años.

Expuestas las líneas fundamentales de la regulación del contrato de arrendamiento financiero en la Ley Concursal, la pregunta que nos atañe sería ¿cuáles son los fundamentos en los que se basan estas dos corrientes?. Si consideramos al leasing como un contrato de tracto sucesivo, nos remitiremos a la interpretación de dicho contrato establecida por la Sentencia del Tribunal Supremo de 4 de diciembre de 2007 en la cual se dice: "contrato atípico por el que una empresa especializada cede el uso de un producto -que ella no ha producido sino que ha sido adquirida de un tercero- en arrendamiento al usuario, con la opción de compra, finalizado el arrendamiento, por un precio, normalmente muy bajo (...) su función económica que constituye su acusa no es otra que permitir a los empresarios que no tienen liquidez o medios financieros para adquirir, desde un principio, la propiedad de bienes muebles o inmuebles, disfrutar de ellos obteniendo la cesión de uso de los mismos, una vez han sido adquiridos para dicha finalidad, según las especificaciones del futuro usuario, por una entidad financiera, la cual, (...), se constituye a cambio en acreedora de una contraprestación a pagar por el arrendatario financiero, consistente en el abono periódico de cuotas -calculadas en función de la amortización del precio y remuneración por el demérito que el uso acarreará a los bienes-, incluyéndose necesariamente una opción de compra a su término, en favor del usuario, con un valor fijo que suele corresponder al resto de precio pendiente de amortizar, y que no impide calificar el contrato como de arrendamiento financiero con independencia de que su montante no se corresponda con el importe de cada cuota".

A modo de resumen, destacaremos de esta corriente, que viene siendo mayoritaria, la consideración del leasing como un contrato sinalagmático de tracto sucesivo con obligaciones pendientes de cumplimiento por:

o la entidad arrendadora, siendo dichas obligaciones:

- la cesión temporal y periódica del uso del bien 
- la obligación de transferir el dominio en el supuesto del ejercicio de la opción de compra.

o el arrendatario financiero concursado, quien tendría las siguientes obligaciones:

- el abono periódico de cuotas, habitualmente con periodicidad mensual

- la contraprestación a la cesión del uso del bien

Según este criterio, se diferenciarían entre las cuotas pendientes del contrato de leasing anteriores a la declaración de concurso y las posteriores. Por ello, debemos de determinar que sólo las cuotas nacidas antes de la declaración de concurso serán consideradas, de acuerdo con el art. 90. 1. $4^{\circ}$ créditos con privilegio especial. Y, para las cuotas posteriores a la declaración de concurso se aplicaría el artículo 61.2 el cual dice: "Las prestaciones a que esté obligado el concursado se realizarán con cargo a la masa. (...)”.

La segunda corriente minoritaria, pero que ha ido tomando una mayor relevancia, de ahí que haya sido tratada en el VII Congreso Nacional de Jueces Mercantiles, considera al leasing, según se ha indicado, como un contrato de tracto único con obligaciones pendientes de cumplimiento únicamente por parte del arrendatario financiero deudor concursado, que serían las cuotas devengadas con anterioridad a la declaración del concurso, como las que se devenguen o deban devengarse con posterioridad a la declaración del concurso. Así, la Sentencia de la Audiencia Provincial de Barcelona, sección 15a, de 9 de noviembre de 2010 dispone: "aunque lo que se transmita es una cesión de uso, la cuota pactada no responde tanto al concepto de renta que compensa la privación temporal del bien por parte del propietario, como a permitir a la entidad financiera recuperar el precio satisfecho para la adquisición del bien, además de una carga financiera que constituye propiamente el beneficio de la arrendadora financiera. Ello justifica la previsión legal que, para caso de incumplimiento, no sólo legitima la resolución con una cláusula penal que, cuando menos, es resarcitoria de la inversión llevada a cabo por el arrendador para la adquisición del bien, sino también la posibilidad de exigir el íntegro cumplimiento del contrato y cobrarse el crédito, con carácter preferente a cualquier otro acreedor, con la ejecución del propio bien. Lo que se traduce en el ámbito concursal en el reconocimiento al acreedor arrendador financiero de un crédito con privilegio especial sobre la totalidad de las cuotas, sin que el artículo 90.1-4 distinga entre las vencidas y las pendientes de vencimiento". $Y$ en otra parte de la sentencia afirma: "Cuatro: A los efectos de la presente apelación, nos interesa advertir si un contrato de leasing pendiente de cumplimiento al tiempo de declararse el concurso de acreedores, lo está respecto de las prestaciones de una sola de las partes o si lo está respecto de las dos. Está claro que el arrendatario financiero, en relación con las cuotas no vencidas, tiene pendiente su cumplimiento, aunque no le fueran todavía exigibles por o estar vencidas. La cuestión es si, a los efectos del art. $61 \mathrm{LC}$, cabe que se encuentran 
pendiente de cumplimiento obligaciones por parte de la entidad de leasing”.Según esta segunda teoría, no cabría la aplicación del art. 61.2 LC dado que no existiría obligación contractual, ya que solo existen obligaciones pendientes a cargo del arrendatario, por ello, se debe regular por el art. 61.1 LC el cual dice: "el crédito o la deuda que corresponda al deudor se incluirá, según proceda, en la masa activa $o$ en la pasiva del concurso". En definitiva, en caso de que sea con anterioridad o posterioridad a la declaración del concurso se aplicaría el art. 90.1.4 LC, citado al inicio de la explicación, calificándose como créditos con privilegio especial. Una vez estudiado el contrato de leasing en la legislación española, pasaremos al estudio de este contrato en la normativa italiana y su aplicación en la Legge Fallimentare (en adelante L. fall).

\section{REGULACIÓN DEL LEASING EN LA LEGGE FALLIMENTARE}

El concepto de leasing viene dado por su origen anglosajón, con lo que nos remitimos a la definición dada anteriormente. Desde el punto de vista de la normativa internacional, Italia, a diferencia de España, sí que ratificó el Convenio de Unidroit recogido en la Legge 14 luglio 1993 n. 259. En el Derecho italiano, la primera definición del contrato de leasing viene recogida en la Legge 183/1976, aunque posteriormente, se establece la regulación como tal contrato en la Legge 14 luglio $1993 \mathrm{n}^{\circ} 259$ art. 1. Antes de analizar el contrato de arrendamiento financiero en la Legge Fallimentare debemos de mencionar los tipos de leasing: el de "godimento" y "traslativo". El primero, de duración que corresponde a la vida económica del bien, se caracteriza: 1) por realizar un análisis, desde el punto de vista empresarial del contrato, en el que interviene una entidad financiera, y una empresa interesada en utilizar los bienes; 2) por subrayar que el objeto sea para el ejercicio de la empresa (usuario), cuya vida económica y técnica corresponda a la duración del contrato; 3) por la naturaleza de las cuotas, que corresponden al uso del bien. En el leasing "traslativo" prevalece el cumplimiento de traslado de la propiedad, por lo que el contrato tiene una causa mixta, el tiempo de financiación y el tiempo de trasferirse; además, a la causa de financiación, se añade la causa típica de la venta. La mayor ventaja práctica que esta figura comporta es la posibilidad para el utilizzatore (usuario) de obtener la propiedad del bien, sin la necesidad de inmovilizar indefinidamente capital disponible. Esta tipología de leasing, dada que la finalidad última es el traspaso de la propiedad, tiene cierta semejanza con la venta del pago aplazado.

Una vez realizado las anteriores precisiones sobre el contrato de leasing, analizaremos el Regio Decreto 16 marzo 1942, n 267, conocida como Legge Fallimentare, la cual ha sufrido importantes reformas. La más relevante con respecto al leasing ha sido la del año 2006, debido a que el legislador ha incluido el artículo 72 quarter para regular de modo uniforme el arrendamiento financiero. 
Este artículo que ha entrado en vigor el 16 de julio de 2006, prevé en su contenido una disciplina mixta; pues recoge, en parte, los principios generales válidos para los contratos pendientes (nuevo art. 72 Legge Fallimentare), y, en parte, aquellos propios del contrato de compraventa a rate (plazos) art. 73 L. Fall. Y la posterior modificación del decreto “correctivo" del 2007, añadió: “avvenute a valori di mercato", (por lo que respecta a la tan conflictiva valoración del bien en el mercado). Lo que sí cabe destacar de esta nueva regulación es la confirmación por parte del legislador de conservar en el mercado la empresa insolvente o, de cualquier manera, de no perjudicar la recuperación, durante o después del cierre del procedimiento, como resulta evidente en el art. 72 que ha declarado ineficaz las "clausole negoziali" (cláusulas jurídicas) que hacen depender la resolución del contrato por el fallimento. Dicha reforma ha establecido que el contrato de arrendamiento financiero se inicia con la obligación por parte de ambos contrayentes hasta el derecho al ejercicio de la opción final de adquisición, lo que se considera una "rapporto giuridico pendente" (contrato pendiente). Así, la aplicación de la nueva regulación está condicionada, como para todas las "rapporto giuridico pendente", a que el contrato resulte validamente perfeccionado, "opponibile al fallimento" (aplicable al concurso), y, al menos en parte, irrealizable por uno de los contrayentes.

Las nuevas reglas del art. 72 introducidas en la reforma de 2006 y modificadas por el d. Leg 169/2007 establecen los efectos del fallimento en la "rapporto giuridico pendente" del arrendamiento financiero, así como regulan la materia no solo para el caso de fallimento de la parte concedente sino también para el supuesto mucho más frecuente de fallimento del utilizzatore (usuario), ya que las problemáticas para asegurar el crédito del concedente derivan de la disolución anticipada del contrato. Se trata de la única hipótesis de contrato de naturaleza atípica expresamente regulada por el legislador en una norma, sin equivalentes en el derecho civil sustancial, que innova con respecto a las soluciones adoptadas por la jurisprudencia y la doctrina. Es, por ello, que cabe destacar de la anterior jurisprudencia las numerosas sentencias en las que se distinguía entre leasing traslativo y de godimento; entre ellas, la de Cass. Civ. 23 Maggio 2008, n 13418. Así, a diferencia de la normativa anterior, la reforma de 2006 establece una regulación para el contrato de arrendamiento financiero, independientemente que se trate de leasing de godimento o de leasing traslativo (anteriormente explicados), optando por una regulación unitaria. Dicha regulación se ha obtenido de los textos normativos tomados: del anterior apartado del art. 72 en el cual contenía la regla general, del apartado 2 del articulo $104 \mathrm{l}$. fall. sobre esercizio provisorio (liquidación provisional), del segundo apartado del art. 73 sobre la "vendita a rate" (venta a plazos) y del art. 1526 cc, sobre la "vendita con riserva dominio" (venta con reserva del dominio).

Se debe especificar que la regulación sobre arrendamiento financiero se contiene especialmente en el art. 72 quarter en el que se extrae en su lectura su 
mención al art. 72, siendo ésta una norma de ámbito general, habiendo sido modificado el art. 72 comma 8 por el Legge 7 agosto 2012, n 134 Conversione in legge, con modificazioni, del decreto-legge 22 giugno 2012 n 83, recante misure urgenti per la crescita del Paese. Analizaremos la regulación de leasing en el fallimento del utilizzatore, dado que es la más frecuente en la práctica. Las opciones que se pueden tomar son la "scioglimento" (resolución) del contrato y restituir el bien, o bien, el "subentro" (continuar) con el contrato. Antes de analizar la resolución del contrato comenzaremos estudiando la segunda opción. El art. 72 quarter no regula los efectos para la continuidad del contrato remitiéndose al art. 72, en el que el curatore fallimentare (administrador concursal) no puede ejercer la opción de continuar o la de resolver el contrato sin autorización de la "comitato dei creditori" (junta de acreedores).

En el caso de continuar con el contrato de leasing (con cargo a la masa), la obligación del curatore fallimentare es la de que se pague en prededuzione (prededucción) las cuotas maturati (vencidas no pagadas) sucesivamente a la declaración de concurso y la de ejercitar la opción de adquisición sobre el pago del precio preestablecido.El decreto correctivo 169/2007 ha modificado el contenido del artículo 74, afirmando que si se continua con el contrato de esecuzione continuata o periodica (ejecución continuada o periódica) se debe pagar íntegramente el precio de la entrega ya realizada, o de los servicios ya suministrados; por tanto, no se debe dudar que la nueva norma sea aplicable también al contrato de leasing, siendo también éste perteneciente a la categoría de los contratos de ejecución continuada o periódica. La continuación por parte del administrador concursal del contrato leasing comporta, por tanto, la obligación por el fallimento de cumplir los contratos en su integridad, debiendo responder de las cuotas vencidas y no pagadas no solo después sino antes de la declaración de concurso. En las diversas hipótesis en las cuales sea dispuesto el esercizio provisorio, en la segunda parte del art. 72 quarter l. fall. establece que el contrato continúe con cargo contra la masa, salvo la facultad del curatore fallimentare de disolución, previa declaración. También para el arrendamiento financiero es aplicable la disposición del art. 72 parrafo 6 l. fall. según el cual son ineficaces las clausulas contractuales que, relacionadas a la declaración de concurso, resuelven automáticamente el contrato, y durante la suspensión ninguna de las partes tiene que cumplir las obligaciones. En la práctica, las cláusulas que relacionan la resolución del contrato con el concurso del usuario están muy generalizadas, al utilizar fórmulas elaboradas por las empresas de leasing en los contratos con los clientes. En caso de resolución del contrato, se aplican las reglas contenidas en los párrafos 2 y 3 del art. 72 quarter l. fall. La nueva disciplina viene indudablemente a resolver algunos problemas de los efectos de resolución del contrato para subsanar más homogéneamente las funciones de financiación del contrato respecto a las funciones de godimento del arrendamiento y traslativo de la venta. 


\section{CONCLUSIÓN}

Como conclusión, cabe destacar que el contrato de leasing viene regulado en la Legge Fallimentare en el art. 72 de forma general y en el art. 72 quarter, de forma específica. En este último es en el que, después de la reforma de 2006, se produce una gran innovación con respecto a las soluciones adoptadas por la jurisprudencia y la doctrina, dado que el legislador opta por regular dicho contrato como único, es decir, sin diferenciar entre los dos tipos de leasing traslativo y de godimento. A diferencia de la italiana, la legislación española, después de la reforma de la Ley Concursal, continúa regulando el contrato de leasing de forma general, careciendo de una norma específica en la que se recoja las interpretaciones de la jurisprudencia y la doctrina, como es el supuesto de las cuotas pendientes después de la declaración de concurso.

\section{BIBLIOGRAFÍA}

ARRIBAS HERNANDEZ, Alberto. (2012) "Derecho Concursal”. Grupo Editorial El Derecho y Quantor, SL.

DIMUNDO FRANCESCPQUATRARO, Bartolomeo. (2011) "La verifica dei crediti nelle procedure concorsuali” Editorial Giuffré.

DI PAOLA NUNZIO, Santi. (2012) "Il fallimento". Editorial Giuffré.GALLEL BOIX, Josep.(2012) "Derecho concursal bancario". Editorial Tirant lo Blanch.

LÓPEZ LÓPEZ, Enrique y MACÍAS CASTILLO, Agustin. (2012) “Comentario práctico a la nueva Ley Concursal”. La Ley Actualidad.

MARTÍN MOLINA, Pedro, GONZÁLEZ BILBAO, Emilio y CARRE DÍAZGALVE, José María. (2012) "La reforma de la Ley Concursal analizada por especialistas” Dykinson, SL.

MARTÍNEZ SANZ, Fernando y PUETZ, Achim. (2012) "Tratado práctico del Derecho concursal y su reforma”. Editorial Tecnos, SA.

PRENDES CARRIL, Pedro. (2012) “Guía práctica concursal”. Editorial Aranzadi, SA.

PULGAR EZQUERRA, Juana y ALONSO UREBA, Alberto. (2009) "Implicaciones financieras de la Ley Concursal". La Ley.

PULGAR EZQUERRA, Juana. (2012) “El concurso de acreedores”. La Ley.

ROMERO SANZ DE MADRID, Carlos.( 2012) "Derecho concursal”. Editorial Civitas, SA.

TAGLIAFERRI, Vera. (2010) "Vendita, permuta, leasing”. Giuffré Editore.

TEDDE FRANCESCAVISENTI, Aurora Bianca. (2010) "Vendita, permuta, leasing”. Editorial Giuffré.

VEIGA COPO, Abel B. (2012) "La masa pasiva del concurso de acreedores". Editorial Civitas. 